\title{
Análise da eficiência de terraços de retenção em sub-bacias hidrográficas do Rio São Francisco
}

\author{
Geraldo M. F. Magalhães ${ }^{1}$
}

\begin{abstract}
RESUMO
Apesar de ser uma prática antiga, o terraceamento apresenta dificuldades relativas ao seu uso, sendo sua eficiência dependente do dimensionamento correto do espaço entre terraços, da lâmina de escoamento superficial, da sua seção transversal e da uniformidade construtiva. Foram estudados terraços de retenção, tipo Nichols, construídos em duas áreas distintas em sub-bacias hidrográficas do Norte de Minas nos municípios de Icaraí de Minas, Pintópolis e Ubaí, MG, no âmbito do Programa de Revitalização de Bacias Hidrográficas do Rio São Francisco. Através da seção obtida na cota mais baixa da crista do camalhão, combinada com a cota mais baixa de sua extremidade, determinou-se seu volume de armazenamento efetivo. Através da relação entre o volume efetivo e necessário, foi possível observar, para Icaraí de Minas, que nas áreas 01 e 02 a eficiência variou de 76,40 a 44,80\%, para Pintópolis, de 9,00 a $63,50 \%$ do potencial volumétrico de acumulação de água nos terraços, não sendo possível fazer a avaliação da eficiência para os terraços do município de Ubaí. Esses resultados evidenciam problemas na eficiência de terraços construídos pelo Programa de Revitalização, para as condições do Norte de Minas Gerais.
\end{abstract}

Palavras-chave: terraço, eficiência, conservação do solo e da água

\section{Analysis of efficiency of retention terraces in sub-basins of the São Francisco River}

\begin{abstract}
Although being an old practice, the terracing still presents relative difficulties to its use, being its efficiency dependent on the correct sizing of the space between terraces, the depth of superficial draining, its transversal section and mainly the constructive uniformity. Terraces of holding, type Nichols were studied, constructed in two distinct areas in sub-basins in the North of Minas Gerais state in Icaraí de Minas, Pintópolis and Ubaí cities, in the scope of the Program of Revitalization of Watersheds of the São Francisco River. By means of the section in the lowest quota of the crest of the ridge, combined with the lowest quota of its extremity, its volume of effective storage was determined. Through the relation between the effective and necessary volume, it was possible to observe that for Icaraí de Minas areas 01 and 02 , the efficiency varied from 76.40 to $44.80 \%$; for Pintópolis, from 9.00 to $63.50 \%$ of the volumetric potential of water holding in the terraces, not being possible to evaluate the efficiency for the terraces of Ubaí city. These results evidence efficiency problems of terraces built by the Program of Revitalization, for the North of Minas Gerais conditions.
\end{abstract}

Key words: terrace, efficiency, soil and water conservation 


\section{INTRODUÇÃO}

A ocorrência frequente de chuvas intensas associadas principalmente ao manejo inadequado do solo, tem aumentado a erosão hídrica constituindo-a como a principal forma de degradação dos solos agrícolas. Práticas incorretas no cultivo podem destruir, em poucos anos, a camada arável do solo que a natureza levou milênios de anos para formar (Bahia et al., 1992).

Este fato tem acarretado aumento dos custos de produção na agropecuária, redução nos lucros obtidos pelos agricultores pela perda de fertilizantes, água e nutrientes do solo, forçando uma necessidade crescente de suas reposições cujas perdas expressam valores da ordem de US\$ 173,6 milhões (Pruski, 2009).

O uso de práticas conservacionistas que aumentem a infiltração e o armazenamento da água no perfil do solo, que intensifiquem a cobertura vegetal e reduzam o escoamento superficial, é recomendável (Dionisio, 2010). Assim, além de controlar a erosão e o empobrecimento do solo obtém-se, como reflexo, melhorias da qualidade da água e a preservação da vida silvestre e do meio ambiente (Bertoni \& Lombardi Neto, 2012).

Várias são as práticas utilizadas para controlar a erosão hídrica em solos agrícolas normalmente divididas em práticas edáficas, vegetativas e mecânicas, as quais apresentam sua eficiência potencializada quando usadas de forma integrada.

Segundo Cantalice et al. (2009), Santos et al. (2009) e Ferreira et al. (2010) uma boa cobertura morta sobre o solo constitui-se como uma das principais práticas para controlar a erosão do solo.

Estudo sobre quantificação da erosão em pastagem com diferentes declives, realizado por Inácio et al. (2007) também demonstrou que a pastagem é uma eficiente cobertura vegetal para proteção do solo.

Projetos de Manejo Integrado dos Recursos Naturais em Sub-Bacias Hidrográficas, com o propósito de reduzir os efeitos negativos da erosão do solo, promover a recarga hídrica das reservas subterrâneas e favorecer a estabilidade dos agroecossistemas estão sendo implantados em municípios mineiros que compõem a Bacia Hidrográfica do Rio São Francisco, tendo seu início pelo Norte de Minas Gerais.

O terraceamento em terras agrícolas é uma das práticas mais difundidas para o controle da erosão hídrica. Terraços são estruturas compostas por um dique e um canal, dispostos no sentido transversal à declividade do terreno, formando obstáculos físicos para reduzir a velocidade do escoamento superficial e ordenar o movimento da água sobre a superfície do solo (Miranda et al., 2004).

Apesar de ser uma prática antiga, o terraceamento apresenta, ainda, dificuldades relativas ao seu uso sendo sua eficiência dependente do adequado posicionamento espacial dos terraços, do dimensionamento correto da sua seção transversal e da sua uniformidade no campo (Griebeler et al., 2005).

Griebeler et al. (1998) relatam, entretanto, que em virtude dos elevados custos de construção e manutenção de sistemas conservacionistas é importante otimizar seu dimensionamento visando satisfazer o controle da erosão e a economia do projeto.

Estudos realizados por Pruski et al. (1995) demonstraram a variabilidade espacial da seção transversal de canais de terraços posicionados em nível, sendo que 22,70 a $41,30 \%$ da seção transversal de terraços foram inoperantes, no que diz respeito à acumulação de água; já Griebeler et al. (1998) realizaram estudos semelhantes e encontraram valores variando de 31,70 a $42,90 \%$.

Para Griebeler et al. (1998) e Pruski (2009) mesmo com o dimensionamento correto do sistema de terraceamento de retenção, sua eficiência é bastante influenciada pelo relevo irregular do terreno devendo acompanhar pontos de mesmo nível e manter sua geometria teórica preservada. Tem-se, então, sua eficiência relacionada ao volume de água armazenado no canal do terraço, o qual é determinado pela sua seção transversal, combinada com a menor altura encontrada ao longo da crista do camalhão e pela obstrução simultânea de suas extremidades. Os aspectos construtivos também são influenciados pelo tipo de solo, pela textura, pelo relevo, pela cobertura vegetal existente e pelo tipo de máquina utilizada. A combinação desses fatores pode alterar a estrutura geométrica projetada para o terraço, além de proporcionar sua ineficiência pela redução da capacidade de armazenamento do escoamento superficial e consequentemente, infiltrado; pode promover graves problemas de erosão, reduzir a otimização dos recursos financeiros envolvidos e diminuir a disponibilidade de água para o ecossistema e para uso humano.

Portanto, o objetivo deste trabalho é analisar a eficiência da capacidade de retenção da água em terraços posicionados em nível, construídos pelo Programa de Revitalização da Bacia Hidrográfica do Rio São Francisco quanto à sua capacidade volumétrica de armazenamento necessária e efetiva.

\section{Material e Métodos}

As avaliações ocorreram nos meses de abril a junho de 2011, em terraços de retenção do tipo Nichols de base média, construídos cortando o solo unicamente do lado de cima do terreno para baixo (Figura 1). O estudo foi realizado em sistemas de terraceamento implantado em 2010 em três subbacias hidrográficas localizadas no Norte de Minas Gerais, nos municípios de Icaraí de Minas, Pintópolis e Ubaí, MG, onde se avaliaram duas áreas por município localizadas, respectivamente, nas coordenadas $16^{\circ} 08^{\prime} 09^{\prime}$ ' $\mathrm{S}$ e $44^{\circ} 41^{\prime} 34^{\prime \prime}$ $\mathrm{W}$; $16^{\circ} 03^{\prime} 05^{\prime}$ ' S e $45^{\circ} 09^{\prime} 14^{\prime \prime} \mathrm{W}$; $16^{\circ} 24^{\prime} 01^{\prime \prime} \mathrm{S}$ e $44^{\circ} 51^{\prime} 40^{\prime \prime} \mathrm{W}$.

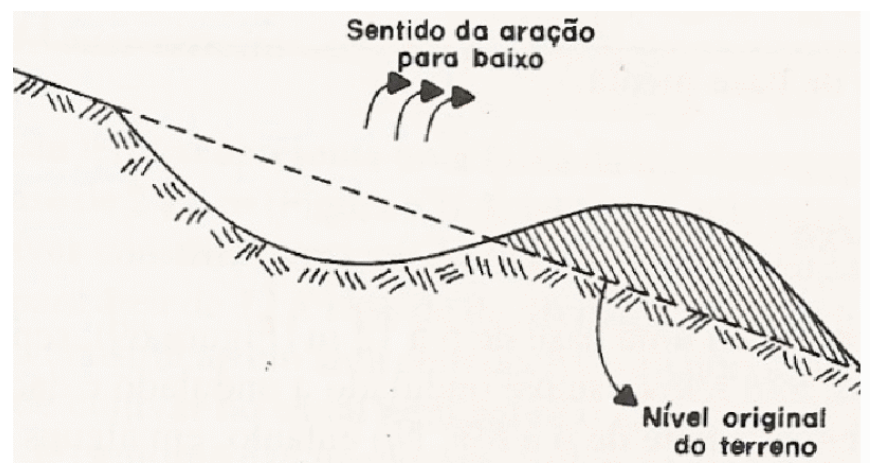

Fonte: Pruski (2009)

Figura 1. Representação esquemática do perfil de um terraço tipo Nichols mostrando o sentido de movimentação do solo, canal e o dique ou camalhão 
De acordo com a classificação de Köppen, o tipo de clima predominante na área estudada é o Aw, caracterizado pela existência de uma estação seca, bem acentuada no inverno, tendo pelo menos um mês com precipitação inferior a $60 \mathrm{~mm}$, em que a temperatura média do mês mais frio é superior a 18 ${ }^{\circ} \mathrm{C}$ (Antunes, 1994).

No município de Icaraí de Minas os terraços foram construídos em solo com predominância do Argissolo Vermelho-Amarelo, textura média, declividade média de $6 \%$, construídos com motoniveladora. A cultura predominante nessas duas áreas identificadas foi a pastagem de braquiária (Brachiaria spp.).

Para o município de Pintópolis o solo predominante também foi o Argissolo Vermelho-Amarelo, textura média, declividade média $3 \%$, cujos terraços foram construídos por motoniveladora; a cobertura vegetal é composta de braquiária.

No município de Ubaí os terraços foram construídos em Latossolo Vermelho-Amarelo, textura arenosa, declividade média de $4 \%$, com arado de 3 discos acoplado ao trator de pneus. A cultura predominante nas áreas identificadas foi a pastagem de capim-andropogom (Andropogon gayanus).

O perfil da seção transversal foi traçado na curva média de cada sistema de terraceamento pré-identificado por município e, com o uso do nível ótico e da mira estadimétrica, foi delineado o perfil da seção em quatro pontos equidistantes dentro de cada curva ao longo do terraço. Para cada seção determinaram-se cotas perpendiculares em cada perfil, por meio de quatro leituras que acompanharam a forma geométrica do canal com início na crista do camalhão e término no ponto de igual altura em direção ao terraço de montante (Figura 2).

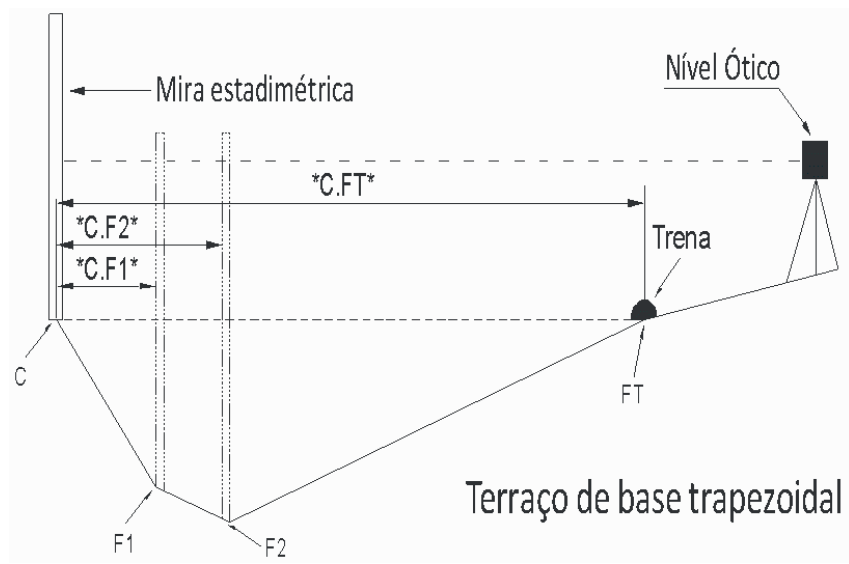

Fonte: Pruski (2009)

Figura 2. Representação esquemática do perfil transversal de terraço, onde $C$ é a cota da crista, $F_{1}$ e $F_{2}$ são cotas do fundo, $\mathrm{FT}$ a cota do fim, $\mathrm{C}-\mathrm{F}_{1}, \mathrm{C}-\mathrm{F}_{2} \mathrm{e}$ $\mathrm{C}$ - FT as distâncias horizontais a cada ponto analisado

O levantamento da área de contribuição para formação do volume proveniente do escoamento superficial entre o terraço avaliado e o de montante, foi obtido com a trena métrica. Foram considerados o comprimento do terraço avaliado e a distância média de três medidas tomadas em direção ao terraço de montante, conforme variação topográfica do terreno (Figura 3).

Para identificar o ponto mais baixo da crista do camalhão (altura crítica) e da cota das extremidades, realizaram-se

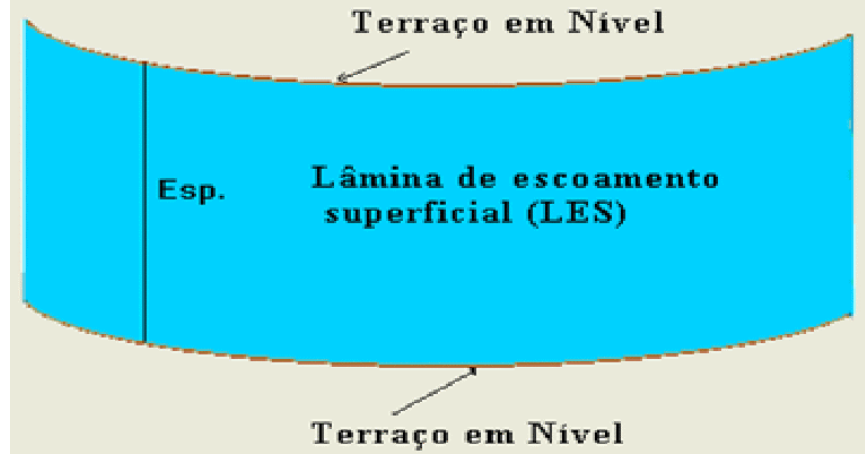

Fonte: Pruski et al. (2006)

Figura 3. Área de contribuição para formação do escoamento superficial

diversas leituras ao longo da crista do terraço e nas suas respectivas extremidades (Figura 4).

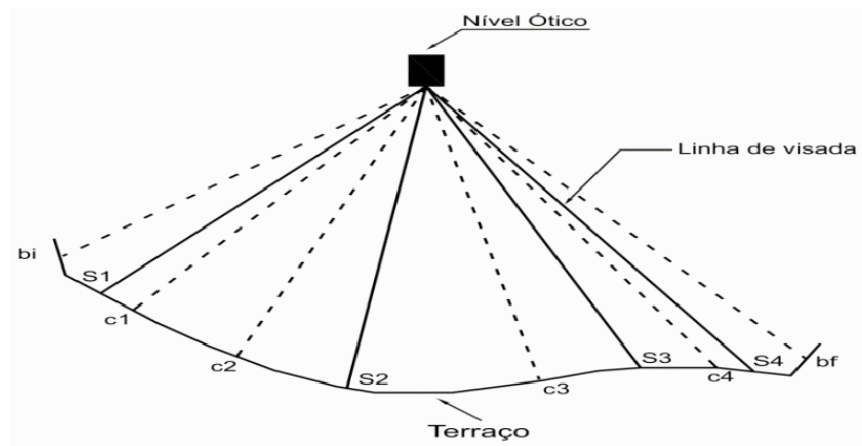

Fonte: Pruski (2009)

Figura 4. Representação esquemática do levantamento de dados de um terraço, onde $\mathrm{S}$ representa pontos onde foram feitos os perfis das seções transversais, C pontos da crista, bi e bf os pontos de suas extremidades

A taxa de infiltração estável da água no solo foi determinada pelo método do infiltrômetro de anel instalado de forma concêntrica, na vertical e enterrado a $15 \mathrm{~cm}$ no solo. Foram usados intervalos de tempo variando de 5 a $120 \mathrm{~min}$ com a infiltração vertical da água medida no interior do cilindro interno. A altura da lâmina nos aneis foi de $5 \mathrm{~cm}$, com variação máxima de $2 \mathrm{~cm}$, conforme apresentam Bernardo et al. (2008). Para cada área à montante da curva média, obteve-se a taxa de infiltração da água no solo pela média de três pontos determinados de forma aleatória.

$\mathrm{Na}$ determinação do escoamento superficial máximo para cada localidade onde a relação entre intensidade, duração e frequência da chuva são conhecidas, foi usada a metodologia proposta por Pruski et al. (1997). Esta metodologia está baseada em fundamentos físicos da engenharia, no balanço da água na superfície do solo e na premissa de que o solo se encontra com umidade próxima à saturação, no momento da chuva de projeto. Para permitir o uso deste procedimento e processar as informações, foi utilizado o modelo computacional Hidros, desenvolvido por Pruski et al. (2006).

Com essas informações determinou-se, para cada seção de terraço, a área de armazenamento necessária (An) e efetiva (Ae) com seus respectivos volumes de armazenamento necessário $(\mathrm{Vn})$ e efetivo (Ve) que, por sua vez, foram determinados pelo 
produto de suas áreas com o comprimento de seus respectivos terraços. Em seguida, obteve-se a eficiência de armazenamento da água no interior dos terraços pela relação $(\mathrm{Ve} / \mathrm{Vn})$ sendo utilizado o modelo computacional Terraltim 1.0, desenvolvido por Miranda et al. (2008).

Tais procedimentos possibilitaram a análise da eficiência dos terraços de retenção quanto à capacidade de armazenamento da água para as condições edafoclimáticas do Norte de Minas Gerais dentro do Programa de Revitalização da Bacia Hidrográfica do Rio São Francisco.

\section{Resultados E Discussão}

Seções de terraços construídos no município de Icaraí de Minas, áreas 01 e 02, estão representadas pelas Figuras 5A e 5B, respectivamente. As seções de terraço da área 01 (A) apresentam irregularidade principalmente quanto à sua cota de crista e da profundidade. A inclinação de taludes à jusante e à montante é suave revelando uma boa capacidade de armazenamento, o que pode ser demonstrado pela área real média calculada em 1,93 $\mathrm{m}^{2}$ (Tabela 1). A cota mais baixa da crista do terraço, $0,65 \mathrm{~m}$, limita a capacidade de armazenamento da água no seu interior a 142,80 $\mathrm{m}^{3}$ (Tabela 2). A área real média da seção encontrada no campo é maior que a área necessária média (Tabela 1), o que representa uma superestimação de $75 \%$ entre elas.

Dentre os dados apresentados para Icaraí de Minas e Pintópolis, na Tabela 2, a maior eficiência obtida por esse sistema de terraços, foi de $76,40 \%$. Apesar de apresentar variação, principalmente na profundidade e na altura da crista, a associação entre as alturas do ponto mais baixo da crista, $0,65 \mathrm{~m}$, com a cota da extremidade do terraço em $0,75 \mathrm{~m}$, propiciou menor

A.

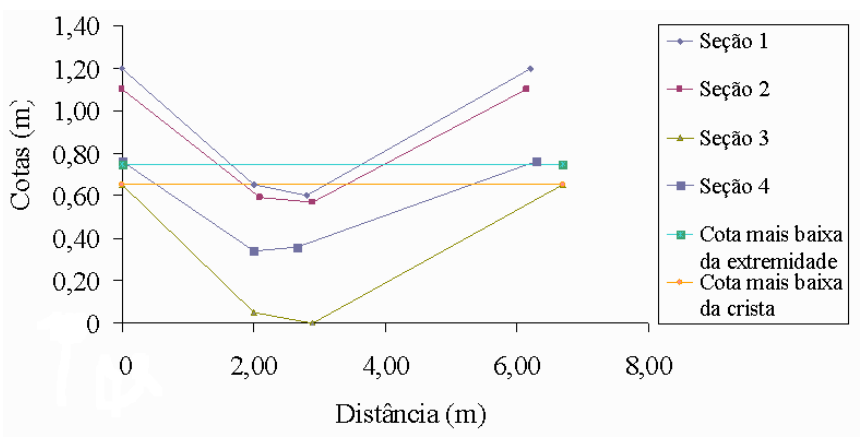

B.

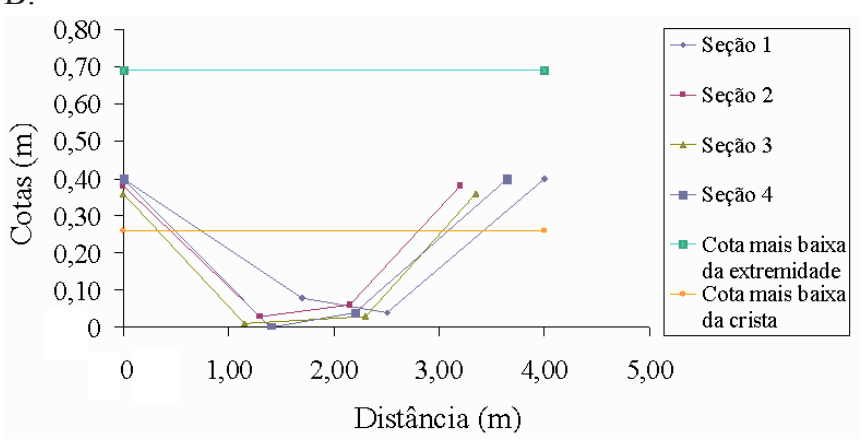

Figura 5. Perfil da seção transversal de canal, altura de crista e de extremidade do terraço na área 01 (A) e área 02 (B) do município de Icaraí de Minas
Tabela 1. Área necessária (An), área real (Ar) e área efetiva $(\mathrm{Ae}), \mathrm{em} \mathrm{m}^{2}$ para terraços avaliados no município de Icaraí de Minas, Pintópolis e Ubaí

\begin{tabular}{|c|c|c|c|c|c|c|c|}
\hline \multirow{2}{*}{ Município } & \multirow{2}{*}{$\begin{array}{l}\text { Área/ } \\
\text { Seção }\end{array}$} & \multicolumn{3}{|c|}{01} & \multicolumn{3}{|c|}{02} \\
\hline & & An & $\mathrm{Ar}$ & Ae & An & $\mathrm{Ar}$ & $\mathrm{Ae}$ \\
\hline \multirow{5}{*}{$\begin{array}{l}\text { Icarai de } \\
\text { Minas }\end{array}$} & 1 & 1,10 & 2,00 & 0,03 & 0,87 & 0,80 & 0,35 \\
\hline & 2 & 1,10 & 1,80 & 0,08 & 0,87 & 0,70 & 0,35 \\
\hline & 3 & 1,10 & 2,40 & 2,40 & 0,87 & 0,80 & 0,46 \\
\hline & 4 & 1,10 & 1,50 & 0,85 & 0,87 & 0,90 & 0,41 \\
\hline & Média & 1,10 & 1,93 & 0,84 & 0,87 & 0,80 & 0,39 \\
\hline \multirow{5}{*}{ Pintópolis } & 1 & 2,10 & 1,20 & 0,14 & 1,70 & 2,40 & 0,93 \\
\hline & 2 & 2,10 & 1,10 & 0,53 & 1,70 & 2,45 & 0,94 \\
\hline & 3 & 2,10 & 1,70 & 0,02 & 1,70 & 2,70 & 1,03 \\
\hline & 4 & 2,10 & 1,30 & 0,05 & 1,70 & 3,00 & 1,42 \\
\hline & Média & 2,10 & 1,33 & 0,19 & 1,70 & 2,64 & 1,08 \\
\hline \multirow{5}{*}{ Ubaí } & 1 & 0,05 & 3,70 & 0,67 & 0,04 & 2,40 & 0,02 \\
\hline & 2 & 0,05 & 2,60 & 0,70 & 0,04 & 2,00 & 0,04 \\
\hline & 3 & 0,05 & 3,20 & 0,52 & 0,04 & 1,80 & 0,13 \\
\hline & 4 & 0,05 & 3,00 & 0,80 & 0,04 & 1,80 & 0,24 \\
\hline & Média & 0,05 & 3,10 & 0,67 & 0,04 & 2,00 & 0,11 \\
\hline
\end{tabular}

Tabela 2. Volume de armazenamento necessário $(\mathrm{Vn})$, volume efetivo (Ve), em $\mathrm{m}^{3}$ e a eficiência, em \% de terraços nos municípios de Icaraí de Minas, Pintópolis e Ubaí

\begin{tabular}{|c|c|c|c|c|c|c|c|}
\hline \multirow{2}{*}{ Município } & \multirow{2}{*}{$\begin{array}{l}\text { Área/ } \\
\text { Volume }\end{array}$} & \multicolumn{3}{|c|}{01} & \multicolumn{3}{|c|}{02} \\
\hline & & Vn & & Ve & Vn & & Ve \\
\hline \multirow{2}{*}{$\begin{array}{l}\text { Icaraí de } \\
\text { Minas }\end{array}$} & & 187,00 & & 142,80 & 196,62 & & 88,14 \\
\hline & $\mathrm{Ef}(\%)(\mathrm{Ve} /$ & $\mathrm{Vn})$ & 76,40 & & & 44,80 & \\
\hline \multirow{2}{*}{ Pintópolis } & & 840,00 & & 76,00 & 685,10 & & 435,24 \\
\hline & $\mathrm{Ef}(\%)(\mathrm{Ve} /$ & Vn) & 9,00 & & & 63,50 & \\
\hline \multirow{2}{*}{ Ubaí } & & 14,50 & & 194,30 & 8,00 & & 22,00 \\
\hline & $\mathrm{Ef}(\%)(\mathrm{Ve} /$ & Vn) & $1.340,00$ & & & 275,00 & \\
\hline
\end{tabular}

variação entre seus volumes efetivo e necessário alcançando a melhor eficiência. Entretanto, por uma questão de segurança, Pruski (2009) recomenda que a menor cota da crista deva estar posicionada a $0,15 \mathrm{~m}$ acima da cota da extremidade do mesmo terraço. Observa-se, então, uma inversão no posicionamento dessas componentes evidenciando erro quanto ao aspecto construtivo. Considerando a eficiência apresentada é possível verificar que $23,60 \%$ da sua seção transversal estão inoperantes; com o produto dessa estimativa pelo volume de canal efetivo no terraço, obtém-se um volume de água não armazenado de $44,10 \mathrm{~m}^{3}$.

Percebe-se, pela comparação entre as Figuras 5A e 5B, que a área 02 (B) apresenta maior uniformidade entre as seções com maior discrepância para seção 1 proporcionada pela menor inclinação no talude à jusante. De forma geral, as quatro seções apresentam suavidade na inclinação dos taludes; também é possível observar que a área real média da seção do terraço, $0,80 \mathrm{~m}^{2}$, é menor que a área necessária para o armazenamento da água, $0,87 \mathrm{~m}^{2}$ representando $92,90 \%$ do seu valor evidenciando, deste modo, seu subdimensionamento em 7,10\%. Assim, analisando unitariamente sua real capacidade volumétrica, obtém-se um volume disponível para armazenamento de 80 $\mathrm{m}^{3}$ de água.

A cota mais baixa da crista, $0,26 \mathrm{~m}$, limita a capacidade de armazenamento da água no terraço enquanto a cota da extremidade, em 0,69 m, não representa, neste caso, 
uma limitação mas deveria, segundo recomendação, estar posicionada no mínimo em $0,15 \mathrm{~m}$ abaixo da menor cota da crista.

Apesar de esses terraços apresentarem maior uniformidade entre as seções, isto não se reflete na sua melhor qualidade visto que atingiu apenas 44,80\% de eficiência. Para este sistema de terraços a baixa eficiência encontrada está associada sobretudo à pequena altura de crista encontrada ao longo do terraço, com apenas $0,26 \mathrm{~m}$ responsável, portanto, pela baixa capacidade de armazenamento de água no interior do canal. A baixa eficiência do sistema contribui para que $55,20 \%$ da sua seção transversal sejam inoperantes que, associada ao seu volume necessário, corresponde a $108,48 \mathrm{~m}^{3}$ de água não armazenada.

Terraços construídos no município de Pintópolis, áreas 01 e 02 , estão representados pelas Figuras $6 \mathrm{~A}$ e $6 \mathrm{~B}$. A área 01 (A) apresenta desuniformidade entre as quatro seções estudadas, sobremaneira entre os valores de cotas de crista e de profundidade sendo a seção 2 a que mais contribui para tal fato. Como a área média real transversal de $1,33 \mathrm{~m}^{2}$ é menor que a média necessária de $2,10 \mathrm{~m}^{2}$, representando $63,30 \%$ do seu valor, demonstra-se seu subdimensionamento em $36,70 \%$. A cota da extremidade na altura $0,24 \mathrm{~m}$, associada à cota mais baixa da crista, $0,28 \mathrm{~m}$, limita a capacidade de armazenamento efetiva de água no interior do terraço, em 76,00 $\mathrm{m}^{3}$.

Dentre as eficiências calculadas esta área representa o sistema de terraceamento com a menor eficiência $(9,00 \%)$. A baixa eficiência obtida está relacionada às pequenas alturas de cotas encontradas para a extremidade e para o ponto mais baixo ao longo da crista do terraço. Referidos fatores são determinantes para que haja uma diferença maior entre o volume efetivo de armazenamento e o volume necessário. Esta variação expressa sua baixa eficiência mantendo $91,00 \%$ de sua seção inoperante correspondendo a um volume necessário de água não armazenado, de 764,00 $\mathrm{m}^{3}$.

$\mathrm{Na}$ área 02 (B) nota-se uma uniformidade melhor entre as seções construídas sendo que a seção 4 é a que mais se afasta das demais, principalmente quanto à sua profundidade. A variação entre as profundidades dos canais é de $0,07 \mathrm{~m}$, proporcionada pela maior profundidade do canal da seção 4 e pela menor profundidade da seção 1 .

A conformação geral das seções está condicionada à inclinação dos taludes sendo mais influenciada, neste caso, pela inclinação do talude à jusante. A área média real dos terraços, $2,64 \mathrm{~m}^{2}$, em relação à média necessária, $1,70 \mathrm{~m}^{2}$, demonstra alto dimensionamento, de 55,30\%.

A cota mais baixa da extremidade em 0,33 m é o principal limitante da capacidade de armazenamento do terraço retratando a baixa eficiência encontrada no sistema, caso em que a cota da crista praticamente não influencia sua capacidade de armazenamento devido à sua boa uniformidade construtiva obtida ao longo de todo o terraço.

Esses terraços apresentaram eficiência de 63,50\% sendo maior que as eficiências encontradas para Pintópolis, área 01 (A) e Icaraí de Minas área 02 (B) mas inferior à de Icaraí de Minas, área 01 (A). Esta eficiência é proporcionada pela boa uniformidade entre as seções de canal e por apresentar uma altura maior encontrada na crista do terraço identificada

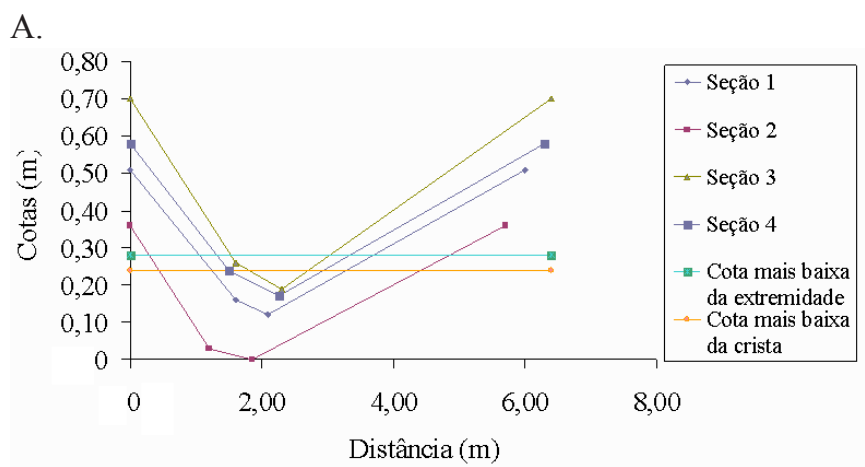

B.
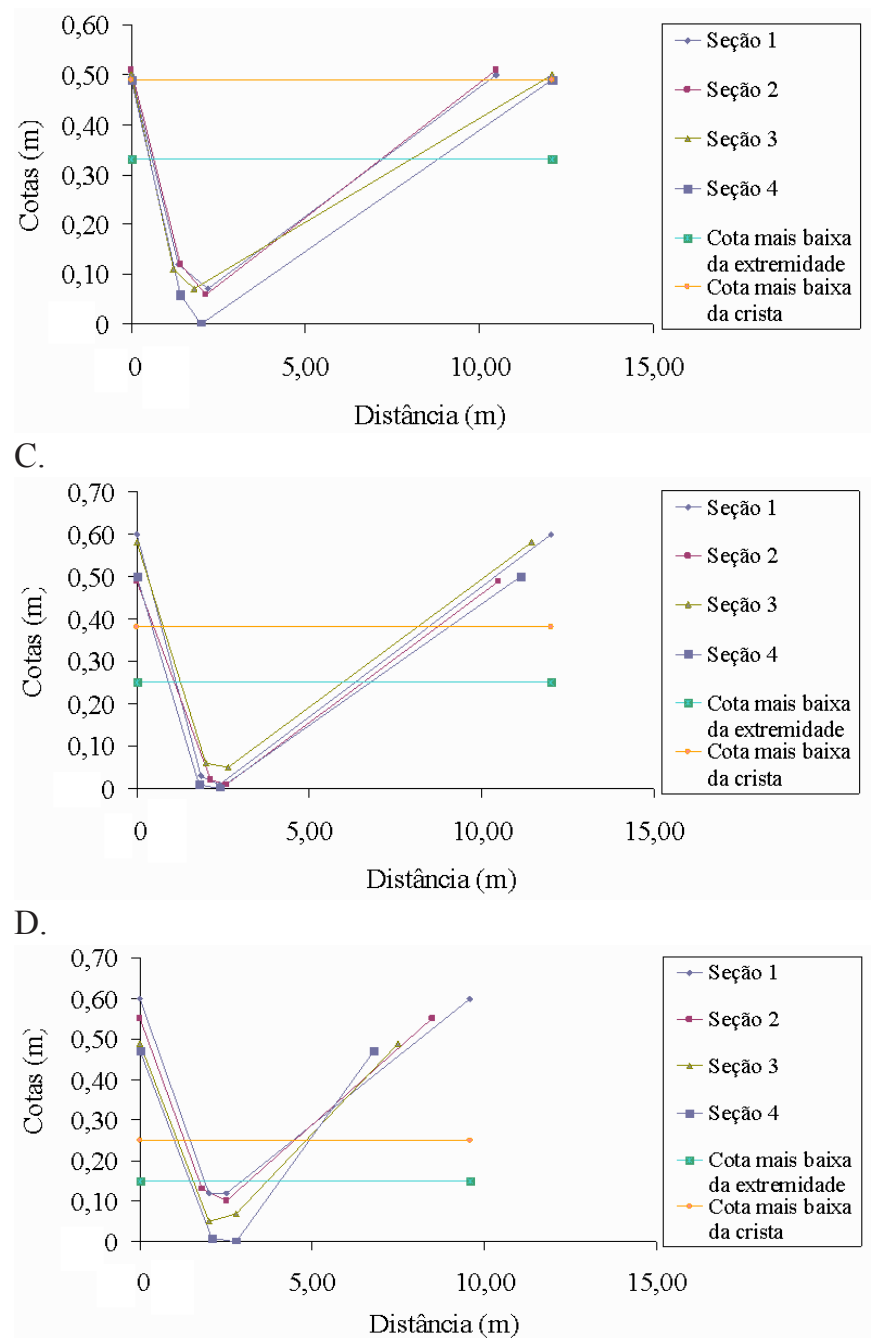

Figura 6. Perfil da seção transversal de canal, altura de crista e de extremidade do terraço na área 01 (A), área 02 (B) do município de Pintópolis, área 01 (C) e área 02 (D) do muncípio de Ubaí

como sendo o local mais baixo, com 0,49 m. Para esses terraços $36,50 \%$ da sua seção transversal estão inoperantes correspondendo a $250,06 \mathrm{~m}^{3}$ do volume necessário de água não armazenada.

Terraços construídos no município de Ubaí, áreas 01 (C) e 02 (D) estão representados pelas Figuras 6C e 6D. Os terraços da área 01 (C) demonstram uma boa uniformidade entre as quatro seções estudadas quanto ao aspecto geométrico. A maior inclinação do talude à jusante influencia no aspecto geral da 
geometria das seções do terraço colaborando para menores disponibilidades de áreas reais. Entretanto, mesmo com esta inclinação maior a área média real das seções, $3,10 \mathrm{~m}^{2}$, é bem superior à área média necessária para armazenamento da água, $0,05 \mathrm{~m}^{2}$. Este fato demonstra a importância de se conhecer a lâmina do escoamento superficial no dimensionamento correto da seção de terraço posicionado em nível (Pruski, 2009). Avaliando a diferença entre tais áreas é possível concluir que há um superdimensionamento deste parâmetro. Fidalski (1998) também identificou, estudando sistemas de terraceamento agrícola no Nordeste do Paraná, estruturas superdimensionadas para o controle da erosão. A cota da extremidade do terraço posicionada em $0,25 \mathrm{~m}$, associada à cota mais baixa da crista em $0,38 \mathrm{~m}$, delimita a capacidade efetiva unitária de armazenamento em apenas $0,67 \mathrm{~m}^{3}$.

Relacionando áreas de seção efetiva e necessária ao comprimento do terraço, é possível determinar sua capacidade volumétrica de armazenamento efetiva e necessária em 194,30 e $14,50 \mathrm{~m}^{3}$. Assim, pela sua diferença numérica, é possível determinar que $179,80 \mathrm{~m}^{3}$ de canal não serão utilizados.

$\mathrm{Na}$ área 02 (D) pode-se observar certa desuniformidade entre as seções, propiciada principalmente pelas variações na profundidade, na cota da crista e no comprimento dos taludes à montante. A maior variação encontrada na profundidade do canal do terraço está representada pela seção 4 , com $0,47 \mathrm{~m}$, em referência à menor profundidade da seção $3, \operatorname{com} 0,42 \mathrm{~m}$.

De forma geral, a conformação geométrica das seções do terraço sofre maior influência pela maior inclinação apresentada no talude à jusante quando comparada com o talude à montante. A cota da extremidade do terraço em $0,15 \mathrm{~m}$, associada à cota mais baixa da crista em $0,25 \mathrm{~m}$, expressa os limites críticos que determinam a capacidade efetiva unitária de armazenamento do terraço, em $0,11 \mathrm{~m}^{3}$.

Analisando os valores encontrados para a área média real, $2,00 \mathrm{~m}^{2}$, e área média necessária, $0,04 \mathrm{~m}^{2}$ das seções, verifica-se que o valor de seção encontrado no campo é bem superior ao necessário para reter o escoamento superficial indicando um superdimensionamento teórico dessa estrutura, em 5.000\%.

Este fato, como ocorre na área 01 (C), reforça a necessidade e a importância em se determinar corretamente a lâmina do escoamento superficial para o dimensionamento correto da seção de terraço posicionado em nível.

Analisando então sua capacidade volumétrica de armazenamento efetiva e necessária no interior do canal de 22,00 e $8,00 \mathrm{~m}^{3}$, respectivamente, nota-se que sua diferença representa $14,00 \mathrm{~m}^{3}$ do terraço, os quais não serão utilizados.

As altas taxas de infiltração estável determinadas nesses solos proporcionaram a formação de pequenas lâminas de escoamento superficial quando comparadas com os outros solos (Tabela 3), fato que determina que o volume necessário do terraço para o armazenamento do escoamento superficial também seja reduzido. Entretanto, o volume do canal construído para reter o escoamento produzido nas duas áreas deste município, é bem superior ao necessário; desta forma, a relação entre esses parâmetros gerou valores de eficiência bem superiores a $100 \%$, como se observa na Tabela 2 , o que torna incoerente sua avaliação não sendo possível, então, determinar valores representativos para este parâmetro.
Tabela 3. Lâmina do escoamento superficial para o tempo de retorno de 8 anos nos municípios de Icaraí de Minas, Pintópolis e Ubaí

\begin{tabular}{lcc}
\hline \multirow{2}{*}{ Município } & \multicolumn{2}{c}{ Lâmina do escoamento superficial (cm) } \\
\cline { 2 - 3 } Icaraí de Minas & Área 01 & Área 02 \\
Pintópolis & 3,93 & 3,22 \\
Ubaí & 6,83 & 5,69 \\
\hline
\end{tabular}

Lâminas do escoamento superficial determinadas neste estudo demonstram valores menores para os solos arenosos de Ubaí em relação ao solo médio identificado em Pintópolis e Icaraí de Minas (Tabela 4); portanto se obtiveram, em consequência, para os solos com maiores taxas de infiltração estável, menores valores para lâmina do escoamento superficial.

Tabela 4. Textura e fração de areia, silte e argila do solo na profundidade de 0 a $20 \mathrm{~cm}$ em dag $\mathrm{kg}^{-1}$

\begin{tabular}{lcccccccc}
\hline \multicolumn{1}{c}{$\begin{array}{c}\text { Fração } \\
\text { do solo }\end{array}$} & \multicolumn{2}{c}{ Icaraí de Minas } & & \multicolumn{2}{c}{ Pintópolis } & & \multicolumn{2}{c}{ Ubaí } \\
\cline { 2 - 3 } \cline { 5 - 6 } Área 01 & Área 02 & & Área 01 & Área 02 & Área 01 & Área 02 \\
Areia grossa & 22,80 & 25,80 & 26,50 & 38,50 & & 13,00 & 15,50 \\
Areia fina & 55,20 & 50,20 & 38,50 & 31,50 & 76,00 & 71,50 \\
Silte & 6,00 & 8,00 & 12,00 & 10,00 & 4,00 & 5,00 \\
Argila & 16,00 & 16,00 & 23,00 & 20,00 & 7,00 & 8,00 \\
\hline Textura & Média & Média & Média & Média & Arenosa & Arenosa \\
\hline
\end{tabular}

Em geral, solos arenosos apresentam maior quantidade de macroporos, o que determina maiores taxas de infiltração em relação aos solos mais argilosos havendo, quase sempre, maior presença de microporos (Bertoni \& Lombardi Neto, 2012).

Segundo Pruski et al. (2006) determinar corretamente a lâmina máxima do escoamento superficial é fundamental para o dimensionamento correto da seção transversal de terraços haja vista que, quanto maior a capacidade de infiltração de água no solo menor será o escoamento superficial produzido e menores podem ser suas dimensões.

Ainda de acordo com Griebeler et al. (2001) em projetos de estruturas para o controle da erosão, como os terraços cujo objetivo é reter e/ou armazenar a água, o conhecimento do volume de água escoado deve ser determinado corretamente para que o sistema dimensionado seja eficaz e economicamente viável. Grandes diferenças encontradas entre áreas de seção transversal necessária e real, ou seja, a que realmente foi determinada no campo, evidenciam que o escoamento superficial não tem sido avaliado corretamente visando ao dimensionamento dos terraços. Considerando este fato e que o custo operacional está relacionado ao movimento de solo, é possível predizer um aumento nos custos de implantação desses sistemas devido ao seu superdimensionamento.

Resultados encontrados por Pruski et al. (1995) avaliando seções de canais de terraços localizados no município de Braganey, PR, e Griebeler et al. (1998) com estudos em três propriedades, sendo duas localizadas no oeste do Paraná e uma na região central de Minas Gerais, acerca da capacidade efetiva de acumulação de água em terraços posicionados em nível, revelaram variabilidade de 58,70 a $78,30 \%$ e 57,10 a $79,60 \%$, respectivamente. Comparando esses resultados com os encontrados neste estudo nota-se que a amplitude de variação encontrada 9,00 a $76,40 \%$ é bem superior aos resultados 
desses dois autores, demonstrando a dificuldade técnica e operacional na locação, execução, acompanhamento e controle na construção dos terraços em projetos desta magnitude.

Os resultados do presente trabalho se direcionam para a possibilidade de se obter maior eficiência com menores custos na implantação de sistemas de conservação de solo e água, principalmente para os terraços. Todavia, é oportuno, no momento do planejamento, considerar as características peculiares das glebas a serem conservadas, além de se adotar método que considere interação adequada entre a relação solo, chuva e planta, práticas de manejo, condições de relevo, geometria do canal, maquinário agrícola, disponibilidade de mão-de-obra qualificada com os aspectos socioeconômicos e ambientais no dimensionamento.

Tendo em vista melhorias no custo operacional e na eficiência de terraços, recomenda-se: posicionar corretamente as extremidades de terraços em relação à crista para aumentar a segurança contra rupturas; utilizar a lâmina máxima do escoamento superficial no planejamento conservacionista; combinar a uniformidade da crista na máxima cota com o posicionamento adequado do terraço a uma seção transversal corretamente dimensionada; inspecionar, avaliar e adequar sistematicamente dimensões de campo, às teóricas prescritas para reduzir os desvios operacionais na construção de terraços e usar máquina adequada às condições do ambiente local, associada ao operador experiente na atividade para propiciar a construção de terraços mais eficientes e econômicos.

\section{ConClusõES}

1. O posicionamento inadequado das extremidades com $67 \%$ e o rebaixamento da crista dos terraços com $33 \%$ dos casos estudados determinam a redução de sua eficiência.

2. Dos seis terraços avaliados $67 \%$ têm suas dimensões superestimadas por apresentar volume de armazenamento real superior ao volume necessário.

3. Diferenças expressivas entre o volume de armazenamento necessário e o efetivo determinam a variabilidade na eficiência de terraços construídos pelo Programa de Revitalização da Bacia Hidrográfica do Rio São Francisco, de 9,00 a 76,40\%.

\section{Literatura Citada}

Antunes, F. Z. Caracterização climática. Informe Agropecuário, v.17, p.15-19, 1994.

Bahia, V. G.; Curi, N.; Carmo, D. N.; Marques, J. J. G. S. Fundamentos de erosão do solo: tipos, formas mecanismos, fatores determinantes e controle. Informe Agropecuário, v.16, p.25-31, 1992

Bernardo, S.; Soares, A. A.; Mantovani, E. C. Manual de irrigação. 8.ed. Viçosa: UFV, 2008. 625p.

Bertoni, J.; Lombardi Neto, F. Conservação do solo. 8.ed. São Paulo: Ícone, 2012. 355p.

Cantalice, J. R. B.; Bezerra, S. A.; Oliveira, O. F. L.; Melo, R. O. Hidráulica e taxas de erosão entressulcos sob diferentes declividade e doses de cobertura morta. Revista Caatinga, v.22, p.68-74, 2009.
Dionisio, H, A, F. Erosão hídrica: Suscetibilidade do solo. Revista Eletrônica Thesis, n.13, p.15-25, 2010.

Ferreira, A. O.; Gonzatto, R.; Miola, A.; Eltz, F. L. F.; Amado, Telmo J. C. Influência da declividade e de níveis de cobertura de solo no processo de erosão com chuva simulada. Revista Verde de Agroecologia e Desenvolvimento Sustentável, v.5, p.182-190, 2010.

Fidalski, J. Sistema de terraceamento agrícola proposto para região noroeste do Paraná. Acta Scientiarum, v.20, p.313316, 1998.

Griebeler, N. P.; Pruski, F. F.; Braga, A. P.; Abrahão, W. A. P. Variabilidade espacial da seção transversal de terraços posicionados em nível. Revista Engenharia na Agricultura, v.6, p.1-11, 1998.

Griebeler, N. P.; Pruski, F. F.; Martins Júnior, D.; Silva, D. D. Avaliação de um modelo para estimativa da lâmina máxima de escoamento superficial. Revista Brasileira de Ciência do Solo, v.25, p.411-417, 2001.

Griebeler, N. P.; Pruski, F. F.; Teixeira, A. F.; Silva, D. D. Modelo para o dimensionamento e a locação de sistemas de terraceamento em nível. Engenharia Agrícola, v.25, p.696-704, 2005.

Inácio, E. S. B.; Cantalice, J. R. B.; Nacif, P. G. S.; Araújo, Q. R.; Barreto, A. C. Quantificação da erosão em pastagens com diferentes declividades na micro bacia do Ribeirão Salomea Revista Brasileira de Engenharia Agrícola e Ambiental, v.11, p.355-360, 2007.

Miranda, A. C. R.; Pruski, F. F.; Silva, D. P.; Mello, E. L. Terraltim 1.0: Ferramenta computacional para avaliação da capacidade de armazenamento dos terraços implantados. Viçosa: UFV, 2008. 9p.

Miranda, J. H.; Duarte, S. N.; Silva, K. O.; Lier, Q. J. Van.; Nova, N. A. V. Dimensionamento de terraços de infiltração pelo método do balanço volumétrico. Revista Brasileira de Engenharia Agrícola e Ambiental, v.8, p.169-174, 2004.

Pruski, F. F. Conservação do solo e da água: Práticas mecânicas para o controle da erosão hídrica. 2.ed. Viçosa: UFV, 2009. $279 p$

Pruski, F. F.; Calijuri, M. L.; Bhering, E. M.; Silva, J. M. A. Metodologia baseada no uso de sistemas de informação geográfica para obtenção de equações de chuvas intensas em qualquer localidade do estado do Paraná. Revista Engenharia na Agricultura, v.5, p.254-265, 1997.

Pruski, F. F.; Griebeler, N. P.; Senn, D. Variabilidade espacial da seção transversal de canais posicionados em nível. In: Congresso Brasileiro de Ciência do Solo, 25, 1995, Viçosa. Resumos expandidos... Viçosa: Sociedade Brasileira de Ciência do Solo, 1995. CD Rom

Pruski, F. F.; Silva, D. D.; Teixeira, A. F.; Cecílio, R. A.; Silva, J. M. A.; Griebeler, N. P. Hidros: Dimensionamento de sistemas hidroagrícolas. Viçosa: UFV, 2006. 259p.

Santos, T. E. M.; Montenegro, A. A. A.; Pedrosa, E. M. R.; Características hidráulicas e perdas de solo e água sob cultivo do feijoeiro no semi-árido. Revista Brasileira de Engenharia Agrícola e Ambiental, v.13, p.217-225, 2009. 